\title{
El problema del cuerpo, el espacio y el tiempo en las pinturas de áni mas
}

novohispanas

Hilda

Domínguez Legorreta CEPE-UNAM

Las pinturas de ánimas, género especial mente favorecido durante los siglos XVII y XVIII novohispanos, poseen una organización interna coherente por medio de la cual se mediatiza una narración espacial y temporal. Al tratar de comprender su estructura interna, al organizar la vivencia del tiempo y el espacio que habitan las al mas que se purifican, se posibilita la comprensión de parte de las experiencias estéticas de aquella sociedad. Un acercamiento no sól o formal de estas obras, sino sobre todo conceptual, nos permitirá ampliar nuestro conocimiento de ellas y así poder acceder a un imaginario distante pero cifrado en estas obras.

El género conocido como "pintura deánimas" nutre de manera importante el mundo visual y simbólico de la pintura colonial de nuestro país. El surgimiento de este tema iconográfico va mucho más atrás de los sigl os XVII y XVIII, sin embargo, en la Nueva España alcanzó características particularísimas al rededor de las cuales intentaremos elaborar ciertas reflexiones. Ocioso resulta discutir la existencia de la entidad Ilamada "al ma" o pal abras similares en diversas culturas: exista o no, es un hecho que hombres y mujeres a lo largo de la historia han creído en su existencia y precisamente, la simbolización de esta entidad ha generado una gestual idad específica, rica en matices y posibilidades de lectura.

La pintura de ánimas pone a prueba los conceptos tradicional es que se tienen sobre el cuerpo y sobre la relación espacio-tiempo. Por ejemplo, respecto al espacio, parece haber ciertas convenciones en cuanto a la dicotomía cielo-infierno: el primero está "arriba", es un "lugar" gozoso y eterno. El segundo, se encuentra "abajo", igualmente eterno, pero es un lugar de castigo y aflicción. En contrapartida, el purgatorio es un concepto lleno de ambigüedadese indefiniciones; concepto que incluso la pro- 
pia I gl esia católica ha tenido que revisar en variadas ocasiones. Lo que es absol utamente importante a considerar en relación al purgatorio es su transitoriedad. Quienes habitan este espacio, saben que es un estadío transitorio, por lo que pueden vivirlo con esperanza, elemento inexistente en el caso de las otras dos realidades metafísicas.

A lo largo de su historia sobre la tierra, el hombre se ha resistido a creer que con la muerte se apague y concluya todo vestigio de vida. Es por ello que a través de los diversos sistemas religi osos se ha al imentado la inquebrantable esperanza de la continuación, de al guna manera, de la vida tras la muerte. Pero, ¿cómo transcurre esta segunda vida? ¿En qué lugar ocurre?; más aún, ¿quiénes experimentan esta segunda vida?

Cultural mente se ha aceptado que el hombre cuenta con una entidad metafísica, componente esencial de su vitalidad, conocida en diversas culturas de maneras distintas, y aunque su nominación cambie, estos conceptos engl oban la idea de una "al ma". Es el al ma la portadora del hálito de vida, la poseedora de las potencias básicas, la que habita la corporeidad material a la cual insufla vida. Admitiendo la existencia del al ma y su diferenciación con el cuerpo, a su muerte, el hombre habita de otra manera, en otros estadíos temporales y espaciales.

En la tradición de la I gl esia católica occidental, se piensa que la morada final de las al mas sea acorde con la virtud o la fal ta de ésta durante la vida terrena. Entonces se puede esperar que el al ma de aquél que cultivó las virtudes necesarias, Ilegue a la Visión Beatífica, la del Dios de J esucristo, allá en la NuevaJ erusalén, en el cielo eterno. Por otro lado, aquellas al mas que no hallen gracia frente a este Dios, deberán sufrir per secula seculorum el martirio, el sufrimiento y el castigo eterno, que no es otra cosa que la ausencia de Dios, la imposibilidad de acceder a su presencia en este mundo de inefable felicidad eterna, que se ha llamado "Paraíso".

A fin de matizar esta radicalización, a partir del siglo XIII, la I gl esia ha reconocido la existencia de un espacio/ tiempo intermedio en el cual aquellas al mas que han sido consideradas dignas de estar en la presencia de Dios son purificadas hasta la perfección, para luego llegar a su 
morada final. Se trata del purgatorio, en donde las almas, a pesar del sufrimiento al que se ven sometidas, gozan de la esperanza de ver un día, cara a cara, a su creador.

Para comprender mejor este género, es pertinente acercarnos a la tradición popular que puede explicar una serie de prácticas culturales con respecto al alma. En palabras de Roger Chartier, habrá que hacer un intento de "descifrar de otra manera las sociedades, al penetrar la madeja de relaciones y de las tensiones que las constituyen a partir de un punto de entrada particular (que para efectos de este estudio se trataría de las pinturas de ánimas) y al consi derar que no hay práctica ni estructura que no sea producida por las representaciones contradictorias, enfrentadas, por las cual es los individuos y los grupos dan sentido al mundo que les es propio."

Siendo como es una creación de la mente del hombre, el al ma posee características antropomorfas. Cuando se trata de dotarlas de una corporei dad para hacer visible lo invisible, por lo general se han concebido con las formas humanas corporales: tienen cabeza, torso, extremidades. Pero en el caso de que las almas estén asociadas al mal, se les pueden hallar en formas monstruosas, desfiguradas, horrendas. Pero no es este el caso de las al mas que habitan el purgatorio, pues hemos dicho ya que estas al mas han sido el egidas para acceder a la gloria infinita y que, en todo caso, requieren de una purificación previa.

Para efectos de su concreción en un lienzo, el al ma ha sido revestida de un cuerpo. Cabe señal ar que no se trata de un cuerpo sano, erguido, sino uno acusando un estado de enfermedad o decaimiento. Se trata de un cuerpo al cual el dolor, el tormento y la angustia han logrado vencer y postrar. Se trata, en suma, de un cuerpo doliente. $Y$ este cuerpo no sólo se duel e por los sufrimientos "físicos" que recibe, sino sobre todo por la incertidumbre de su situación. En efecto, aunque este cuerpo sabe que "algún día"2 estará ya liberado de los sufrimientos corporales $-\mathrm{y}$ al emplear estos términos se evidencia una vez más la dificultad de no emplear conceptos propios de la realidad humana para una realidad intangible, como lo es el alma-y gozará de la visión de Dios, no sabe cuando llegará ese momento, lo que hace su situación más exasperante. Como lo afirma J esús Luis Barrios en su
Roger Chartier. Elmundo comorepresentación. Historia cultural: entre la práctica y la representación, p. 49.

2 Concepto humano necesario para establecer un futuro impreciso e indefinible en el tiempo propio del purgatorio. 
3 José Luis Barrios Lara, "El cuerpo doliente", en El cuerpo aludido, cat. de la exp., del mismo nombre, México, p. 163.

4 Idem. texto El cuerpo doliente" "el dolor es antes que nada una paradoja, la de la incertidumbre por el porvenir y la de la angustia por el descanso ante la presencia instantánea y amenazante del sufrimiento". Este dolor se ve reflejado efectivamente en la posición que adquieren estos cuerpos, tendientes a perder su verticalidad para ceder a la horizontalidad, postura propia de la enfermedad y el sufrimiento. Y sin embargo, estos personajes poseen en sus rostros un dejo de esperanza; se trata de rostros Ilenos de súplica y arrepentimiento. Se podría pensar que hay cierto grado de disasociación entre aquel los cuerpos y sus rostros: los primeros, caídos y vencidos, los segundos, al entadores y esperanzados. Este aspecto puede establecer una particularidad de este género, el cual se convierte por esta característica en una mediación con respecto a las codificaciones gestual es que les son propias al paraíso y al infierno.

En este sentido, la gestualidad, mediación cultural del dolor, adquiere una importancia relevante. Si los gestos dan sentido a la comunicación ¿qué es lo que estos cuerpos y su gestual idad quieren comunicarnos? Por un lado, a través de esa gestualidad, exposición de la interioridad, se nos quiere dar a entender posi blemente, que el dolor se resignifica, se recodifica al sublimarse y devenir sacrificio, vía para la santificación, acceso a la "Promesa Eterna". De esta forma, el dolor que sufren los que habitan el purgatorio se relativiza, en cuanto transitorio y medio para al canzar la felicidad. Pero por el otro, y en sentido inverso, el sentido de transitoriedad significa también que no hay una radicalización en la representación del dolor.

Plásticamente, la gestualidad de los cuerpos dolientes de las ánimas del purgatorio vínculo indisoluble, como señala Barrios en el texto anteriormente citado: "en la gestual idad, el al ma se descubre irremediablemente atada a la carne"4 —requieren de una aproximación teórica desde una estética del dolor y del horror, a través de la cual se encuentren cualidades estéticas al gesto del dolor. Se trata sin embargo, de mediar la experiencia por una explicación de algo inexplicable, ya que el dolor es siempre individual, intransferible e inexplicable. Heahí la necesidad de contextual izarlo, al situarlo en un lugar 
determinado, en donde se hallen los instrumentos de martirio que enfaticen el dolor provocado. En cuanto al espacio del purgatorio, volveremos más adelante.

Retomo a al gunas características de las ánimas: es frecuente atribuirles al gunos rasgos del vivo al que perteneció. Es así que encontramos almas irascibles, amigables, tímidas, tristes (recordemos "La Llorona"). Asimismo, exigen de los vivos, recuerdo y culto, pues en dado caso de que ello no ocurra, se corre el riesgo de su presencia atemorizante entre nosotros o incluso que se vuelvan nuestras enemigas. Por otro lado, reciben con gusto las oraciones, las alabanzas, y llantos dirigidos (por ello las plañideras) a ellas. Ello nos Ileva a considerar el siguiente hecho singular.

Las al mas sienten. Se les concibe como poseedoras de una sensi bilidad igual a la de los vivos; sienten todo tipo de agentes externos: el frío, el calor, el fuego, el peso de la tierra, los vientos, todo ello puede afectarlas. Asimismo, están regidas por las leyes físicas de la naturaleza, por lo que no pueden cruzar ríos, sino es a través de un puente; deben entrar a una habitación por una puerta o "vestirse" para protegerse del frío. Es decir, el imaginario popular las dotas de una corporeidad semejante a la realidad humana, acaso para hacerlas más asequibles a su comprensión.

Es por ello que las al mas - Ilamadas también ánimaspueden ser convocadas, invitadas a la mesa familiar e invocadas para interceder por los vivos. Se les atribuyen ciertos poderes o dones suprahumanos, a través de los cuales se pueden obtener favores especiales. Por otro lado, se desea que se marchen lo más pronto posible, proveyéndolas incluso de mediosfísicoso imaginarios - barcas, zapatos, caminos-para que puedan hacerlo. Ello se debe a que al tiempo que se añora la presencia del vivo, se teme al alma del difunto.

En esencia, gracias a la corporei dad de que se les dota, a las ánimas se les habla, se les trata y considera como si fueran habitantes del mundo de los vivos. Ya sea que se trate de una antigua creencia, de un dogma religioso, de un consuelo o de una simple teoría, las ánimas fortal ecen la fe y la esperanza de un después de esta vida.

Pero ello quiere decir que las ánimas, además de po- 
5 Paul Ricoeur, Tiempo y narración, configuración del tiempo en el relato. pp. 116-117. seer o posi blemente por poseer esta corporeidad, de donde se deriva su gestualidad, podemos deducir su capacidad de actuar. A partir de esta idea, se puede considerar la posibilidad de realizar una análisis estructural de la narración interna del pasaje visual. Esto es, en el accionar, en el obrar de estas ánimas, que manifiestamente se mantienen en actividad constante, hay una finalidad. Como lo señala Ricoeur en cuanto a la fenomenología del obrar, "las acciones implican fines [...] que remiten a motivos". Más adelante agregará que "un acontecimiento físico conduce a otro acontecimiento físico"y finalmente señal a que "las acciones tienen agentes [... ] estos agentes actúan y sufren en circunstancias dadas". ${ }^{5}$ Ello quiere decir que con sus movimientos - gestual idad en acciónlas suplicantes y Ilorosas ánimas esperan lograr un acontecimiento físico, el de su traslado a otro espacio por la fuerza poderosa del Creador. De ahí la mediación simbólica del estiramiento como súplica. Incluso, esta acción de súplica es repetida por los intercesores que frecuentemente piden por la salvación de las ánimas. Es por ello que el cuerpo, entonces, junto con su sufrimiento, se dobla a si mismo en actitud humillada, reducida a su condición vulnerable y frágil. De esta forma, la semántica de la acción hace posible la narración, aunque no sólo ésta. Es por ello que trataré de acercarme a los otros dos aspectos que la posibilitan: tiempo y espacio. En todo caso, esta narración aspira a un orden interno, en donde se pueda identificar un principio, desarrollo y fin.

Para ello, es necesario reconocer que habrá sobre todo que buscar el núcleo de estos conceptos en el mundo empírico (como lo es el conocimiento del alma y purgatorio), en el de la incertidumbre, carente de leyes. Se trata en primera instancia de recuperar las características del pensamiento complejo, mismo que sugiere evitar la visión unidimensional y que ofrece alivio ante la imposibilidad de escapar a la incertidumbre.

En este sentido, la representación de las ánimas, con todas las características mencionadas líneas arriba y que les son atribuidas, descansa en un principio dialógico: las ánimas, improbables en el mundo visual, adquieren una representación que les es necesaria para existir en el mundo de los vivos; las ánimas son incorpóreas, pero 
requieren de la corporeidad que posi bilite su representación plástica, como se hace al referirse al concepto "ánima". Solamente así pueden devenir vehículo de explicaciones doctrinarias que no podrían efectuarse si no fuera por esta representación de lo "in-representable". Lo afortunado de esta situación dial ógica es que constantemente se integra al observador en este proceso creador. Se vuelveel vínculo, el aportador delasignificación, el creador del significado último de esta relación.

Concretamente, es necesario prestar atención a las condiciones y a los procesos quellevan las operaciones de construcción de sentido. Ello permitirá ir configurando ese universo conceptual del cual se habló anteriormente y que tendrá como /ei motiven esta primera fase la construcción del purgatorio como un espaciofísico situado en un tiempo determinado.

La construcción del purgatorio como espacio conceptual en donde selleva a cabo la purificación de las al mas que pretenden regresar a su Creador ha tomado cientos de años. Sus inicios se remontan a los primeros tiempos dela Edad Media, aunque la creencia - ola necesidad de creeren que tras la vida, el hombre es aún capaz de mantener cierto control de lo que sucede es mucho más antigua, quizá tan antigua como la misma existencia del hombre.

La idea del purgatorio va adquiriendo forma; esta construcción va aparejada con la idea de los espacios, su función y especialización, que no se inicia sino hacia el siglo XVIII. En un tiempo de expansión territorial, se intenta "colonizar" el más allá; el hombre se refugia en la esperanza de poder encontrar el espacio descrito por Dante, en donde las al mas tendrán la oportunidad de purificarse para poder presentarse a su Señor.

¿Cabría entonces preguntarnos, el cómo los hombres de estos periodos históricos percibían sus espacios, sus funciones y las jerarquías que asignaban a cada uno de ellos? Si y no. Si porque final mente el hombre logra duplicar su realidad vital en una incorpórea, imaginaria. Un ejemplo de ello es la transferencia del modelo familiar 
humano a los model os de diosas y dioses de todos los sistemas religiosos en donde de la misma manera encontramos a un Padre-Dios, Madre-Diosa, Cristo-Hermano. Luego, la concepción que de su espacio tiene, la forma en que lo usa y se apropia de éste, puede a su vez ser reproducido en un mundo irreal, el del más allá.

Afirmo que no, porquea la vez la construcción conceptual de un espacio como el purgatorio requiere de mucho más quela percepción del espacio físico en el que se vive. A este concepto concurren además ideas sobre la vida después de la muerte, la resurrección, la posibilidad de prolongar la vida, la idea del pecado y su redención o perdón, los temores de la época - y de todas las épocas con respecto a la muerte- las enseñanzas y doctrinas de los padres de iglesia al respecto, en fin, se constituye en un evento cultural multifactorial.

En este proceso, es indudable la influencia que tuvieron las Cruzadas que facilitaron el descubrimiento de nuevas rutas y de nuevos territorios geográficos. Una nueva visión ampliada del mundo aparece y con ello una nueva cartografía se abre paso, empleando por primera vez una incipiente topografía. De esta misma manera, se ensaya una nueva cartografía del más allá ampliada, y Ilena de vastos territorios. La necesi dad de demarcar sus espacios, de apropiarse de sus terrenos en el plano humano, Ilevan al hombre a pretender una demarcación parecidas en el más allá.

Pero sobre todo, el triunfo del purgatorio lo es en la medida que es un triunfo de la razón, que se ve reflejada en una visión nueva de las dimensiones temporales y espaciales que el hombre puede habitar. Es además el vivo reflejo de los avances en Ia justicia social de la Alta Edad Media, así como la reformulación del concepto del pecado y la penitencia. Es a la vez que temido, un espacio de esperanza en el cual se podrán saldar a aquellas deudas que en vida no se vieron satisfechas.

En las obras que intentan reproducir lo jamás visto, los purgatorios ofrecen espacios bien demarcados, existe un arriba-abajo; una izquierda-derecha; delante-atrás. Posiciones importantísi mas cultural y teológicamente hablando, por ejemplo: Cristo bajóa los infiernosy al tercer día ascendióa los ciel os; está sentado a la derecha del Pa- 
dre; el Espíritu Santo descendió sobre los apóstoles en Pentecostés. En el purgatorio entre el fuego abrasador se hallan las almas penitentes que claman por la intercesión de un ser divino, que se encuentra siempre en la región superior, la de los el egidos. Los espacios, además, se comunican: existe siempre un medio de contacto entre ambas dimensiones: un escapulario, un cordón franciscano, un rosario. De esta manera, a través de objetos de la devoción popular, quedan unidos el ciel o y el purgatorio. Los espacios, sin embargo, en este último lugar, no parecen estar distribuidos para favorecer a nadie en especial, trátese de un papa, un rey o un mendigo. El lugar es horrible todo, todo lo quema y lo abrasa.

Las ánimas existen, pero su existencia se da en un espacio determinado. Como Merleau-Ponty señala, el ser es siempre ser en situación. El problema de la especialidad del purgatorio es la imposibilidad de situarlo específicamente en al gún lado, físicamente hablando. ¿Cómo aplicar entonces, las relaciones arriba-abajo, deIante-detrás, izquierda-derecha? Sin embargo, en las representaciones plásticas se hace al usión a estas ubicaciones. Con ello selogran descripciones en cuanto a jerarquías, a la proximidad o lejanía del cielo, a la profundidad de las cuevas en que las al mas habitan. Por otro lado, la ubicación de los diversos espacios ultraterrenos -cielo, purgatorio, infierno-, no encuentra dificultad en su proximidad física en estas representaciones, ya que el artista hábilmente logra separarlos a través de el ementos pictóricos. Pero, ¿estarán igualmente juntos/ separados en la conciencia del que observa estas obras?

Llevado a un plano colectivo, el espacio del purgatorio ofrece la oportunidad a esa masa informe y anónima que es la sociedad, el recuperar el reconocimiento de los distintos grupos social es que la conforman. Los lienzos que nos ofrecen visiones de este lugar, nos muestran siempre una variedad de personas que en vida debieron pertenecer a diferentes capas sociales y dedicarse a muy variadas actividades. Encontramos hombres y mujeres de diversas edades y estados físi cos y al gunos nos indican que fueron sacerdotes, incluso papas y que a quienes el purgatorio reci be en las mismas condiciones, sin contemplaciones ni preferencias reuniéndolos a todos en un mismo 
espacio físico, a diferencia de la realidad humana.

Esta manera de visualizar el castigo general izador, en un espacio común, permite dilucidar a una sociedad que si bien tendría que recorrer un largo trecho antes de deponer monarquías absolutistas, iniciaba ya la larga cadena de cuestionamientos acerca de la divinidad, o, mejor dicho, de la invulnerabilidad divina de los gobernantes civiles y eclesiásticos.

Es posible que ante la visión de tan horrendos sufrimientos los hombres modificaran sus conductas y actitudes, lo cual era el objetivo de este género de pinturas. La sociedad novohispana, altamente cohesionada al menos en cuanto a las creencias religiosas se refiere, compartiendo val ores comunes y aceptados por la mayoría, pudo construir el problema de su muertey de lo que después de ella vendría. En este contexto, las pinturas de ánimas son producto de la necesidad de creer en que no todo estaba escrito con la muerte, de que la muertefísica no era el fin de la vida. Existía en el consciente compartido la posibilidad de continuar en contacto ultraterreno, entre vivosy muertos; estos últimos acceden a un espacio purificador en el que, si bien sufrían temporalmente, al término de dicho sufrimiento gozarían de la Visión Beatífica, la de su Creador. La misma necesidad ontológica que se quiere satisfacer en vida, se exacerba ante la muerte, transe que obliga al hombre a preguntarse acerca de esta "morada final" en la que habitará eternamente.

La posi bilidad de construir una representación del objeto en la conciencia, que a la postre resul ta en una imagen, requiere además del espacio - sentido externo de la representación-, del tiempo - sentido interno de la representación-. Como principios de la sensi bilidad a partir de los cuales se ordenan las sensaciones, las relaciones entre ambos resultan indisolubles. Ahora, ¿qué decir del tiempo propio de un espacio ambiguo, indeterminado? Por que la conjunción de ambos elementos - espacio y tiempo-determinarála manera en queloscuerpos -áni- 
mas encarnadas- existen y obran. El tiempo del purgatorio es distinto a aquel que transcurre en el cielo y en el infierno, porque a diferencia de éstos, el tiempo del purgatorio contiene la promesa del futuro. Quienes lo habitan saben que su situación es finita, transitoria. Este tiempo se "vive" en el deseo, deseo de futuro, de eternidad. Surge de esta manera un cuestionamiento fenomenológico que tiene que ver con la relación temporal entre Ia Incertidumbre-Esperaque se traduce en la narrativa de las obras a manera de Tensión-Distensión y que se resuelve a través de la mediación semántica y simbólica de objetos codificados como recursos de salvación antes mencionadas: rosarios, escapularios, cordones, etc.

Sin embargo, el del purgatorio es un tiempo paradójico, ya que parece no tener efectos en quienes lo viven, lo transcurren. ¿Cómo puede un ánima, cuerpo simbólico y corpóreo a la vez, sufrir el abrazo de las Ilamas, sin terminar de consumirse jamás? ¿acaso el tiempo, acción que transcurre, no transcurre para esta ánima? En estas obras presenciamos una doble narrativa donde cada elemento adquiere un valor simbólico derivado de lo "absurdo" e ilógico de la rel ación entre todos los elementos que constituyen la obra. Es obvio que se trata de una configuración del tiempo diferente a aquella del tiempo real en que habita el hombre, sujeto a otras condiciones y leyes. 


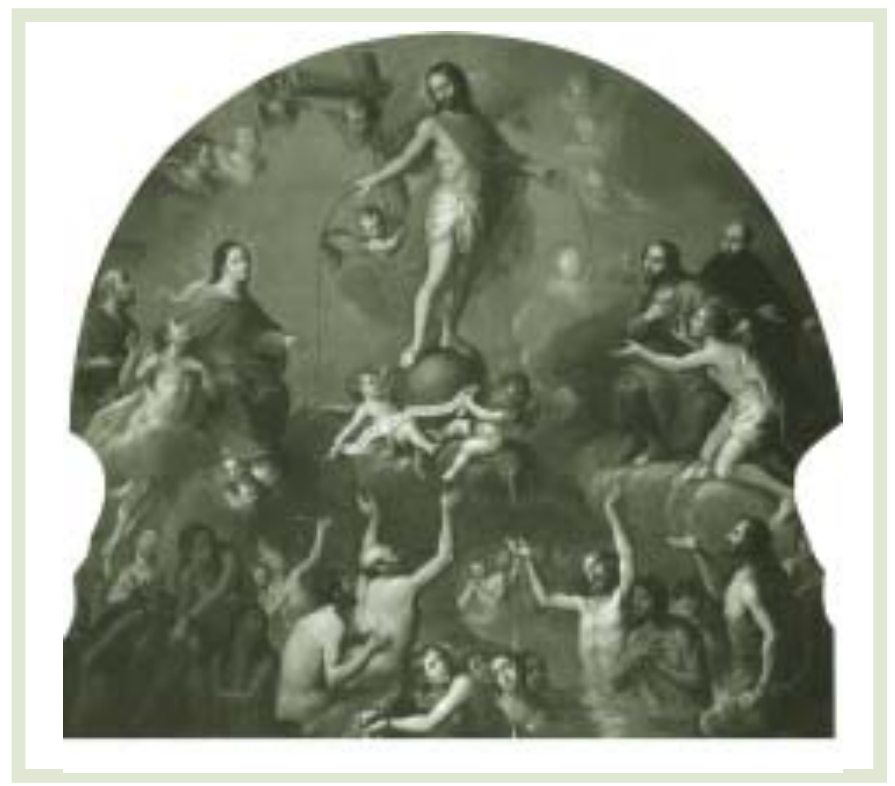

Miguel Cabrera, Alegoría de la preciosa Sangre de Cristo, siglo XVIII.

Habrá que iniciar diciendo que esta obra es una exaltación de la Sangre de Cristo y no una pintura de ánimas. Sin embargo, ambos temas han sido aquí conjuntados, de manera muy lógica, ya que si hay un medio purificador por excelencia, purificación esperada por las ánimas, es la sangre de Cristo.

Se puede observar que el espacio ha sido dividido en varios niveles y que los actores que los habitan son diferentes sobre todo en su condición de "santos" o "pecadores". La figura principal, la de Cristo, habita un espacio celestial, superior, desde donde los otros ámbitos pueden ser contemplados. Este Cristo resucitado no duda en vertir su sangre (con toda la carga simbólica y vital de este fluido) para dar la purificación a quienes lo esperan. La sangre, que brota de la cinco llagas se derrama en lo que parece ser un torrente sin fin. Pequeños amorcillos son admiti dos en este santísi mo lugar, reservado tan sólo para el Hijo de Dios. Este espacio está determinado por un triángulo atectónico, del cual el mundo que sostiene 
a Cristo es el vértice más agudo, al tiempo que guía la lectura hacia los espacios inferiores. En este ámbito la luz se aclara, el espacio se abre y se puede observar la santidad plena.

En el espacio intermedio, podemos observar que los habitantes no son divinos, sino hombres y mujeres que por sus méritos han al canzado la santidad y por ello gozan de la contemplación de Dios en la forma del Redentor. Este espacio intermedio en la composi ción está determinado por el uso de nubes que dividen las áreas, así como por el uso de una paleta que hace que contrasten los tres ámbitos, el emento importante también para enfatizar las distintas dimensiones del sentido del tiempo.

En este espacio intermedio podemos observar al go de sumo interés. En primer lugar, flanqueando a su Hijo, podemos ver a María por un lado y a San J osé por el otro. Dada su condición casi perfecta, se encuentran los más próximos a Cristo, en términos espacial es. Estas tres figuras, las de la Sagrada Familia, logran equili brar la composición al construir un triángulo, tectónico esta vez, que se opone al anteriormente descrito. Al lado de cada uno de ellos, se encuentran dos santos, hombres comunes que Ilevaron una vida ejemplar por lo que ahora están ante Dios, aunque su proximidad física no es tan cercana como las de María y J osé. Estas figuras corresponden a Ias personas de San Pedro y San I gnacio de Loyola, el primero junto a la Virgen y el segundo al lado de San J osé. Ambos aparecen en actitud orante, de súplica, más que de adoración o veneración. Sin embargo, y este detalle particulariza mucho la obra, a estas parejas antes descritas - María/ San Pedro, San J osé/ San I gnacio se une una tercer figura que, en ambos parejas, representa una ánima del purgatorio (del sexo masculino los dos, si se me permiteesta afirmación), quienes luego de un periodo de purificación, están accediendo al siguiente nivel o espacio físico, en donde habitan ya los santos. Este espacio se convierte en ámbito intermediador, la "antesala" a Dios. Precisamente habitan aquí los "intermediarios", santos y santas cuya proximidad física con Cristo les permite apelar a Él para obtener el perdón.

El espacio inferior se ha reservado -como ha sido codificado desde el inicio del arte- para los pecadores quie- 
nes aún habrán de pasar por un proceso de purificación antes de acceder a la gloria. Es importante mencionar que, pese a que aquí no se muestra, debe existir aún un cuarto nivel, el reservado al infierno, en donde habitarán por toda la eternidad aquell os que al no al canzar la gracia de Dios han sido condenados para siemprea su ausencia. En otras palabras, las almas que habitan el purgatorio, aunque en apariencia sufren las mismas penas que aquellas que habitan el infierno, son, a diferencia de éstas, bienaventuradas, pues ya han sido escogidas para ir a Dios.

En relación a la construcción del espacio, se pueden identificar una suerte de cuevas, Ilenas todas de almas en pena, que piden clemencia en medio de las más terribles Ilamas. Hecho muy interesante, Ios habitantes de este espacio son hombres y mujeres, de diferentes edades y características físicas, que recuerdan hasta cierto punto el género de pintura de castas, muy prolijo durante el siglo XVIII. En contraste con aquel los rostros, los cuerpos que reciben el castigo no reflejan el verdadero dol or que se supondría sienten al estar rodeados de Ilamas. Estos cuerpos han sido cuidadosamente distribuidos, agrupados en distintas áreas compositivas, unas más luminosas que otras y pareciera que estos agrupamientos se rigen bajo un criterio de género. En el tercer plano podemos observar a un hombre que, portando una tiara papal, nos habla de la democratizadora acción del purgatorio: cualquier persona puede llegar a él.

Por lo que se observa, en este espacio se puede caminar, subir una roca o bajar aún más. Es un espacio amplio, pero dada la cantidad de pecadores en proceso de purificación, se percibe reducido en su capacidad.

Es interesante observar el cómo tres ámbitos físicos tan distanciados en el imaginario col ectivo-cielo, tierra, purgatorio-se unen en esta obra de manera natural y congruente. Las transiciones entre uno y otro se dan suavemente; no nos molesta la proximidad que hay entre lo superior y lo inferior, así como la presencia intermediadora cielo-tierra de los santos. Las distancias se acortan gracias a los víncul os establecidos por la sangre de Cristo, las nubes, los brazos extendidos.

No menos importante es el manejo de las distintas narrativas temporales empleadas por Cabrera. En el pla- 
no divino, entendemos que el tiempo es eterno, Dios es el que era, el que esy el que será. No hay pasado, no hay futuro, sólo un presente perfecto, eterno.

El espacio intermedio contiene una narrativa temporal de distensión, simbolización de la transición y por ello de momentaneidad. Las al mas han sido rescatadas por los intercesores, y ahora pasan por un momento transitorio antes de llegar a la morada definitiva. Quizá aún habrán de esperar a ser Ilamados por Cristo; a pesar de ello, intuimos este tiempo más breve que aquél del que aún tendrán que esperar quienes habitan el purgatorio.

Finalmente, el tiempo que transcurre en el ámbito del purgatorio, distinto a los dos anteriores, contiene la promesa del futuro, por lo que es también un tiempo transitorio. Aunque este tiempo es ambiguo y para algunas al mas será más largo que para otras, el futuro llegará y la promesa se cumplirá. En ello radica la esperanza que puede alentar a estas al mas sufrientes: el gozo de Dios al gún día ll egará.

\section{BIBLIOGRAFÍA}

BARRIOS LARA, J osé Luis, "El cuerpo doliente", en El cuerpo aludido. Cat. de la exp. Instituto Nacional de Bellas Artes, México, 1998.

BURKE, Peter, Historia y teoría social. México, Instituto Mora, 1997.

CHARTIER, Roger, El mundo como representación. Historia cultural: entre la práctica y la representación, Barcelona, Gedisa, 1995.

LE GoFF, J aques, El nacimiento del purgatorio. Madrid, Taurus Ed., 1981.

MeRLEAU-PONTY, Maurice, Fenomenología dela percepción. México, Origen/ Planeta, 1985. (Obras maestras del pensamiento contemporáneo)

MORIN, Edgar, Introducción al pensamiento complejo. México, Gedisa.

Ricoueur, Paul, Tiempo y narración. Configuración del tiempo en el relato. México, Editorial S. XXI.

VoN Heting, El hombre necrotropo. Estudios de psicología criminal, vol. XI, Madrid, ESPASA-CALPE, 1981. 
